Proceedings of the 50th Hawaii International Conference on System Sciences | 2017

\title{
A Dynamic Network Measure of Knowledge Evolution: A Case Study of MIS Quarterly
}

\author{
Jiexun $\mathrm{Li}$ \\ Western Washington University \\ jiexun.li@wwu.edu
}

\author{
Jiyao Chen \\ Oregon State University \\ jiyao.chen@oregonstate.edu
}

\begin{abstract}
Citation measures are the central metrics to assessing the impact of an article, the viability of research streams, the career success of scholars, as well as the quality and status of journals and academic units. While measuring the magnitude of the future usage, they cannot capture the substantial effects that an article may have on the subsequent use of its predecessors - whether it amplifies or disrupts the existing literature. We embrace that it is imperative to not only assess its impact but also assess how an article reinforces the existing research streams or breaks into a new stream to understand its true effect. Accordingly, we introduce a new, dynamic measure, and conduct a case study using all articles published between 1979-2016 at MIS Quarterly to illustrate the validity of the new measure, and conclude with some future research topics and implications.
\end{abstract}

\section{Introduction}

The structure of knowledge evolution distinguishes between two routes to knowledge creation. The first is called normal science [1], which is firmly built on one or more past scientific achievements. Under the region of normal science that implicitly defines the legitimate problems and methods of a research field, scholars committed to the same rules and standards for scientific practice; the knowledge gained is cumulative. The second is called scientific revolution or paradigm change, which is taken to be the non-cumulative developmental episodes in which an older paradigm is replaced in whole or in part by an incompatible new one. For example, Copernican astronomy replaces Ptolemaic, Einstein's Theory of Relativity replaces Newtonian's mechanisms, which in turn replaced Aristotelian dynamics. In short, new research may amplify or disrupt the existing knowledge.

Despite the substantive and theoretical importance of differentiating between these two routes of knowledge creation, no quantitative measures exist to capture the distinction [2]. Systematic explanations for why, when, and how new knowledge has different effects on their context remain elusive. Assessment of knowledge dynamics traditionally relied on detailed case studies [1]. Quantitative studies are almost exclusively based on forward-citation counts of a work, such as impact factor, five-year impact factor, and h-index, and lead to insightful meaning and implications. However, the literature's focus on citation counts and citation-based measures of impact has a limitation. Although such measures can reflect the magnitude of a work's later use, they often fail to capture other dimensions of knowledge change in terms of differentiating revolutionary scientific breakthroughs from practice-oriented work [2]. Focusing on impact of a new work without considering how it relates to extant knowledge creates bias and incomplete understanding of knowledge evolution.

The quest for citation impact without distinction between two routes of scholarship may at least partially contribute to several limitations of the current management literature. First, it is widely acknowledged that there are few original theories in the management field, which is argued to largely result from manager scholars' overreliance on borrowing from other disciplines, such as economics, psychology and sociology, rather than pursuing an indigenous approach [3]. Second, leading scholars such as Weick and Mintzberg have criticized that top management journals favor deductive rather than inductive research, ideas derived from well-known rather nascent theories, literature-driven research rather than phenomenadriven research, and methodology rigor rather than novelty[4]. Third, while scholars without the western training are expected to have a unique position to initialize new theories due to their different experience and national culture, under the pressure to publish in highly cited journals, they fall within the confines of well-known Western theories, rather than pursuing indigenous issues for theoretical innovation [4]. For example, while they are becoming important players, East Asian scholars are unlikely to take groundbreaking theorizing positions because they believe that top management journals are unlikely to be impressed by new theories they develop [4]. As a result, their success comes largely from a close adherence to the Western research paradigm and their research is becoming indistinguishable from those by Western scholars in terms of guiding theoretical framework and 
methodologies. Even though national culture can be a visible research topic to generate new theories, a culture-general approach is dominant [5].

In this study, we build on Funk and Owen-Smith's dynamic measure of technological change [2] and extend it to a dynamic network measure of knowledge evolution, which captures the effects that a new article has on the use of its predecessors in the future development. Such a dynamic network measure is important to complement the citation impact because, unlike citation measures that only capture the magnitude of the later usage of an article, our new measure captures the effect of an article on its predecessor in future development. A new article as a new node can reshape the network of articles by shifting scholars' attention to or away from the knowledge they built on [2]. In other words, the new measure captures the direction of its effect related to extant knowledge: whether an article reinforces the status quo of the existing literature, or disrupts the existing literature with a new stream.

In the following, we first review the existing measure of scholarship and their limitations, then introduce the new, dynamic measure, conduct a case study using all articles published in 1979 2016 at MIS Quarterly (MISQ) to illustrate the validity of the dynamic measure of scholarship, and conclude with some future research and its research implications.

\section{Related work}

\subsection{Existing measures of impact}

Many quantitative measures view articles as a variable in their impact, i.e. the extent to which they are later used [2]. Although the real impact of an article is hard to assess, citations of articles are increasingly used as a criterion to assess the impact and the viability of research streams, the career success of scholars, and the quality and status of journals and academic units [6]. Leung laments that citation impact has become "the sine quo non of scholarship assessment" [4] (p.510). Accordingly, schools and departments have adopted internal policy that encourages scholars to target high-impact journals, some universities even only reward "hits" at A-journals. Many journal editors aim to raise journals' impact factor as their primary objective. Some scholars have described impact factor as "The Number That's Devouring Science" [7]. Impact measures are attractive because they reflect the intuitive idea that new articles offering big improvements over existing literature should be more widely cited than those with small refinements.
However, impact measures suffer several limitations. First, since impact measures of an article focus on the amount of its later usage, they miss a key substantial distinction between articles whose value is from reinforcing the trajectories which they originate from and those whose value results from disrupting the current stream [2]. Hence, the impact measures are valid to assess the extent to which an article is used, but they cannot provide insights into how the article is used, particularly how its usage shapes the directions of future development in the context of existing scholarship. The latter is the central issue of the evolutionary theory of change $[1,8,9]$. Second, both normal science or practice-oriented research and novel research can have large number of citation, so the impact factor cannot distinguish their differences, which can have important policy implications. Third, the citation count of an article or journal is influenced not only by its later usage, but also type of research such as literature review vs. novelty research and the popularity of a field. For example, it is well-know that Management Science publishing high-quality novel research has low impact factor and Journal of Management publishing review pieces by largely summarizing the exist knowledge has a high impact factor.

With the advance of information technology, scholars can access a much boarder range of information than before, but due to the limitation of scholars' attention and time, they have to be selective about what journals will be their focus. Therefore, it is rational to choose the higher impact journals as citation impact signals their powerful status. At the same time, article citation is primarily influenced by reputation of journals [6], high impact journals become selffulfilling, perhaps leading to winner-take-all and convergence in management journals all scholars aim at [4].

In short, the existing impact measures cannot capture the substantial effects that new articles may have on the subsequent use of their predecessors or the evolution of a broader stream. We embrace that, to understand an article's effect, it is necessary to not only assess its impact, but assess how an article fits into existing research streams or apart away from them by influencing the future work in using its predecessors. By extending the Funk and OwenSmith's dynamic measure of technological change, we develop a new measure below to overcome the limitation of citation measures.

\subsection{A dynamic measure}


According to Funk and Owen-Smith [2], a dynamic measure for evaluating scholarly impact should have the following features:

- $\quad$ Structural (in a network sense): How it affects the use of other articles rather than its own use. How is an article used in the existing literature, or how does an article reshape the literature?

- Dynamic: the extent to which an article changes the use of other literature over time. This captures the idea that new articles emerge in the context that are comprised of other research [8].

- Emergent: capture the effect ex post in the context of its use rather than ex ante in the context of its discovery.

- Continuous: capture degrees of amplification and disruptiveness rather than using category classification.

- Valenced: to distinguish between disrupting and amplifying scholarship.

We follow these guidelines when designing out dynamic measure of knowledge evolution.

\section{Measure Development}

In this paper, we develop a graph-based measure, disruptiveness index. Unlike citation count that measures an article's impact by the magnitude of its own use, our measure quantifies the extent to which an article consolidates or destabilizes the subsequent use of the prior arts on which it builds.

\subsection{Basic measure}

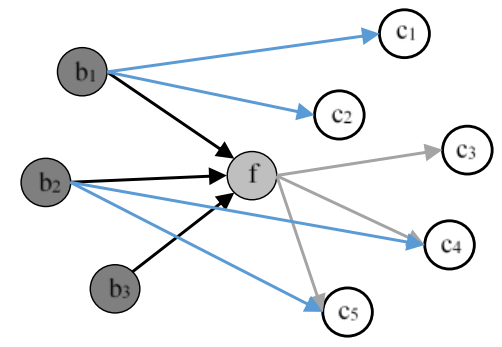

Figure 1. A tripartite citation graph

Our measure is defined based on the citation relationships among research articles in a tripartite directed graph $G=\left(V_{1}, V_{2}, V_{3}, E\right)$, see Figure 1. In this graph, we have three types of vertices and an edge set.

- $\quad V_{1}$ : focal article(s) $f$ 's;

- $V_{2}$ : prior art $\{b\}$, which are cited by $f$ in its bibliography; and
- $V_{3}$ : forward citations $\{c\}$, which are new articles that published after $f$ and cite $f$ or its prior arts.

- $\quad E$ : citation links $\{e\}$, in which each edge $x ® y$ represents an article $x$ is cited by an article $y$.

For a new article $c$ in $V_{3}$, if it considers work in $V_{1}$ and $V_{2}$ relevant and important, there are three ways of attaching a to the network:

1) $c$ cites $b$;

2) $c \operatorname{cites} f$

3) $c$ cites both $b$ and $f$.

In [2] Funk and Owen-Smith defined an index that measures a patent's disruptiveness on all of its prior arts as a whole. In this study, we modify their definition and introduce a new measure $D_{i t}$ to quantify the disruptive impact of focal article $f$ on a particular prior art $b_{i}$ in $\left\{b_{1}, \ldots, b_{m}\right\}$.

For a focal article $f$, its prior art is represented as a set $\mathbf{b}=\left\{b_{1}, \ldots, b_{m}\right\}$, where $m$ is the number of articles cited by $f$. Set $\mathbf{c}=\left\{c_{1}, \ldots, c_{n}\right\}$ represents forward citations to article $f$ and/or its prior art $\mathbf{b}$ at time $t$. We use $i$ to subscript $f$ 's prior arts in $\mathbf{b}$ and $j$ to subscript $f$ 's subsequent articles in c. The disruptiveness of article $f$ on a prior art $b_{i}$ is defined as:

$$
D_{\mathrm{it}}=\frac{1}{n_{t}} \sum\left(-2 f_{\mathrm{jt}} b_{\mathrm{ijt}}+f_{\mathrm{jt}}\right)
$$

where $n_{t}$ is the number of forward citations to $f$ and/or $b_{i}$ in c at time $t$,

and

$$
f_{\mathrm{jt}}= \begin{cases}1 & \text { if } c_{j} \text { cites the focal article } f \\ 0 & \text { otherwise }\end{cases}
$$

$$
b_{\mathrm{ijt}}= \begin{cases}1 & \text { if } c_{j} \text { cites the focal article's prior art } b_{i} \\ 0 & \text { otherwise }\end{cases}
$$

This measure $D_{i t}$ indicates the disruptiveness of the focal patent $f$ on its prior art $b_{i}$.

Based on this definition, the three different ways for a new article $c_{j}$ to join the citation network will have different implications on the focal article $f$.

1) $c_{j}$ cites $b_{i}$ but not $f: f_{j t}=0, b_{i j t}=1$, hence $D_{i t}=-$ $2 * 0 * 1+0=0$. The new article considers the prior art $b_{i}$ more important than $f$. Article $f$ has zero effect on $b_{i}$.

2) $c_{j}$ cites $f$ but not $b_{i}: f_{j t}=1, b_{i j t}=0$, hence $D_{i t}=$ $2 * 1 * 0+1=1$. The new article considers the focal article $f$ more important and discards the prior art $b_{i}$. This indicates that $f$ may be based 
on $b_{i}$ but have introduced a shift from $b_{i}$ in its knowledge creation process.

3) $c_{j}$ cites both $b_{i}$ and $f: f_{j t}=1, b_{i j t}=1$, hence $D_{i t}=$ $-2 * 1 * 1+1=-1$. The new article considers both $b_{i}$ and $f$ important. Therefore, $f$ did not disrupt but amplify the importance of $b_{i}$ in the literature.

Specifically, for the citation network in Figure 1, we can calculate the disruptiveness of $f$ on its three prior arts $b_{1}, b_{2}$ and $b_{3}$ as follows:

1) $f$ on $b_{1}: D_{1 t}=(0+0+1+1+1) / 5=0.60$;

2) $f$ on $b_{2}: D_{2 t}=(1-1-1) / 3=-0.33$;

3) $f$ on $b_{3}: D_{3 t}=(1+1+1) / 3=1$.

In this example, the article $f$ is shown to be most disruptive on $b_{3}$, as indicated by the greatest score $D_{3 t}$ $=1$. None of the new articles that cite $f$ also cites $b_{3}$ in that they consider $f$ more important than $b_{3}$. For articles $b_{1}$ and $b_{2}$, even though they both have three citations, they receive totally different disruptiveness from $f, 0.6$ and -0.33 , respectively. Among the five new articles that cite $b_{1}$ and $f$, two of them cite $b_{1}$ only but not $f$, while the other three cite $f$ only but not $b_{1}$. The positive score $D_{1 t}=0.6$ indicates that there seems to be a knowledge shift from $b_{1}$ to $f$. On the contrary, among the three new articles that cites $b_{2}$ or $f$, two of them cite both $b_{2}$ and $f$, while only one of them cites $f$ but not $b_{2}$. The negative score $D_{2 t}=-0.33$ indicates that $f$ is built upon $b_{2}$ but does not seem to destabilize the position of $b_{2}$ in the literature.

\subsection{Aggregate measures}

So far, we have defined a measure, $D_{i t}$, which quantifies the effect of a specific focal article $f$ on one of its prior art $b_{i}$. Now, let us take a global look at a citation graph, in which each node is an article and each link is a citation from an article $i$ to an article $j$ ( $j$ cites $i$ ). Using the measure defined above, we can calculate the disruptiveness score on each citation link (i ${ }^{\circledR}$ j), which indicates the disruptiveness of article $j$ on its prior art $i$.

In such a directed graph representing a citation network, we can further define a number of aggregate measures that can infer the importance of each article in the literature of this field.

\section{- In-degree}

In-degree is defined as the number of in-links pointing to a node. Specifically, in a citation network, the in-degree represents the number of references cited in the bibliography. This number does not change over time. In Figure 1, since $f$ has three prior arts $b_{1} \sim b_{3}$, its in-degree is always 3.

\section{- Out-degree}

Out-degree is defined as the number of out-links coming out of a node. Specifically, in a citation network, the out-degree represents the number of times this article has been cited. Unlike the in-degree, the out-degree does change over time as an article may receive more citations as time goes by. In Figure 1, since $f$ has three forward citations $c_{3} \sim c_{5}$ so far, its outdegree is 3 at this time.

\section{- Weighted average in-degree}

Each citation link is associated with weight, i.e., the disruptiveness score $D_{i t}$. Thus, for a focal article $f$, we can calculate the weighted average of all $D_{i t}$ 's on its prior arts to measure its overall disruptiveness at time $t$. In Figure 1, the weighted average in-degree of $f$ is $(0.6$ $-0.33+1) / 3=0.42$. A great weighted average indegree means that new articles consider the article more important and tend to cite this article other than its prior arts. Thus, the article tends to be disruptive and lead to knowledge shift in this field.

\section{- Weighted average out-degree}

For an article that is cited by other articles in the citation network, the weight on each citation link indicates the disruptiveness of the citing article on the focal article. Thus, for a focal article $f$, we can determine the weighted average of all disruptiveness scores of the citing articles at time t. In Figure 1, the weighted average out-degree of $f$ is the weighted average of the disruptiveness scores it received from $c_{3} \sim c_{5}$. A great weighted average out-degree means that new articles consider the article's citing articles more important and tend to cite them rather than the focal article. In other words, this article or topic is becoming obsolete and replaced by others in the field.

\section{A case study on MIS Quarterly}

MISQ is widely regarded as one of the most prestigious journals in the information systems discipline since it was first established in 1977. During the past four decades, MISQ has shaped and witnessed the evolution of information system research as a scientific discipline. In this study, we apply our proposed measures on articles published in MISQ over the 40 years of period, in order to identify impactful articles that have played critical roles in shaping the information systems field and illustrate the different 
meanings and implications of the disruptiveness index from citation counts.

\subsection{Data collection}

We collected citation data of MISQ articles from the Web of Science. Although MISQ was established in 1977, the Web of Science's database does not seem to contain the first two volumes of MISQ, Vol. 1 in 1977 and Vol. 2 in 1978. Hence, our data set only contains 1,287 articles published in Vol. 3(1) in 1979 Vol. 40(1) in 2016. For each MISQ article, we collect its metadata, including Web of Science access number (unique identifier), year, volume, issue, authors, title, number of cited references, number of times cited, and list of citing articles. Thus, starting from the 1,287 MISQ articles, we follow their total of 76,769 citations and build a citation network of 27,780 articles. Such a network represents the chronicle development history of MISQ over the past 40 years.

\subsection{Citation graphs}

We divide the 40 years from 1979 to 2016 into four 10-year stages (1977 and 1978 were not included due to lack of data on the Web of Science). The number of MISQ articles included in our four citation networks is listed in Table 1. Articles without any citation relationships (i.e., neither citing any prior MISQ articles nor cited by any articles) were not included in the citation networks.

Table 1. Number of MISQ articles in the four citation networks

\begin{tabular}{|c|c|}
\hline Years & \# of articles \\
\hline $1979 \sim 1986$ & 110 \\
$1987 \sim 1996$ & 381 \\
$1997 \sim 2006$ & 653 \\
$2007 \sim 2016$ & 1126 \\
\hline
\end{tabular}

For each stage/decade, we calculate the disruptiveness indices of all articles that have been published so far. We are also able to visualize the citation network at each stage in Figure 2 (a) (d). In these graphs, each node is an MISQ article and each directed edge is a citation link, on which the thick end connects the citing article. The size of a node represents the number of citations the article has received so far. The color of the node represents the age of the article. Newer articles are in warmer colors while older articles are in cooler colors. The color of an edge indicates the sign of the disruptiveness score, i.e., red (solid) being positive, blue (solid) being negative and gray (dotted) being zero. The width of an edge indicates the magnitude of the disruptiveness. For the sake of visibility, we only include the top 200 nodes with the highest citations in each of these four graphs and label the top 20 most cited articles by the first author and year.

\subsection{Finding the most disruptive articles}

In this study, we are interested in finding the most significant MISQ articles that have helped to shape and define the MIS field. Therefore, we calculate the weighted average in-degree of each MISQ article to represent its disruptiveness.

For each of the four decades of MISQ, we rank all articles by the weighted average disruptiveness index and identify the top five articles, as shown in Tables 2 (a) (d). The column "Citations by year" is the number of citations the article has received so far in the Web of Science core collection under Science Citation Index Expanded (SCIE), Social Science Citation Index (SSCI), and Arts \& Humanities Citation Index (A\&HCI). The last column is the weighted average disruptiveness index of the article in that year.

As shown in Tables 2(a) (d), several most cited MISQ articles are also included in the list as the most disruptive ones. For instance, Davis's 1989 article "Perceived usefulness, perceived ease of use, and user acceptance of information technology" is the most cited one in the history of MISQ (4294 in 2016) [10]. It also has the highest disruptiveness score (0.9779) in 2016. Nevertheless, articles with high disruptiveness score may not necessarily all be the ones with the most citations. A good example is Watson et al.'s 2010 article "Information systems and environmentally sustainable development: energy informatics and new directions for the IS community." By far, this article has received 67 citations, which is far less than some of the most cited articles in MISQ, partially because it was published only six years ago. However, its disruptiveness score (0.9645) is the second highest among all MISQ articles in 2016. This article is considered one of the seminal works in the new stream of IS research on environmental sustainability, which has gained a lot of attentions in recent years. 


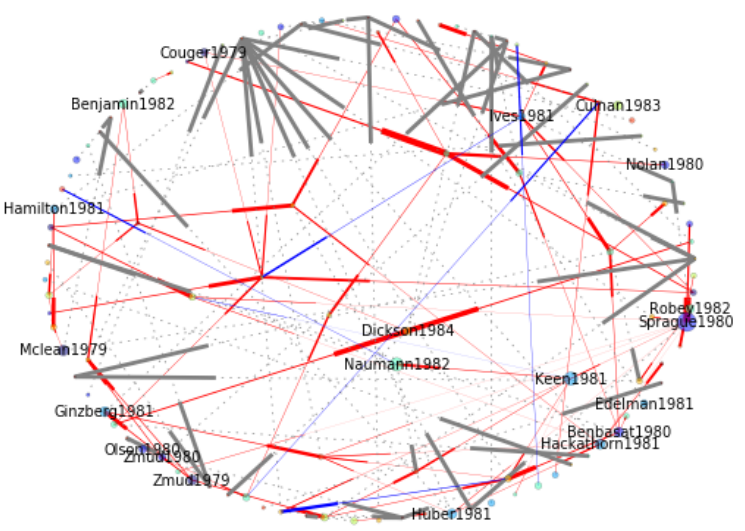

(a) $1977 \sim 1986$

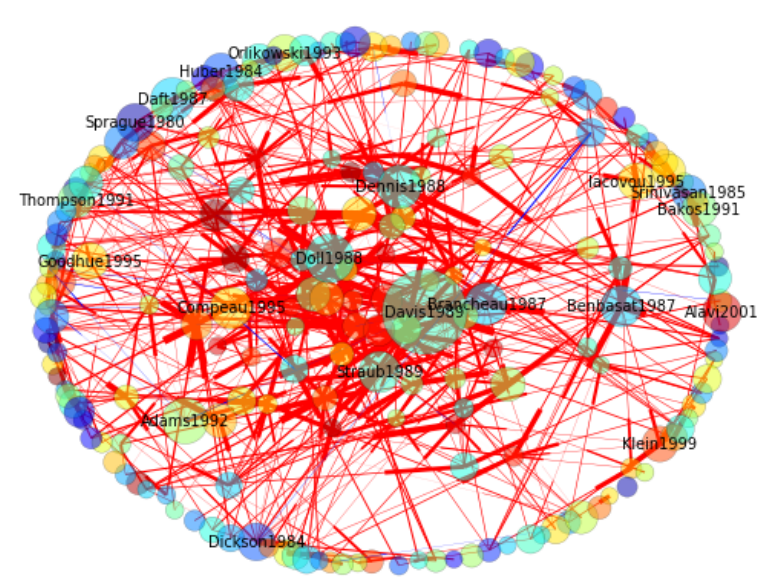

(c) $1997 \sim 2006$

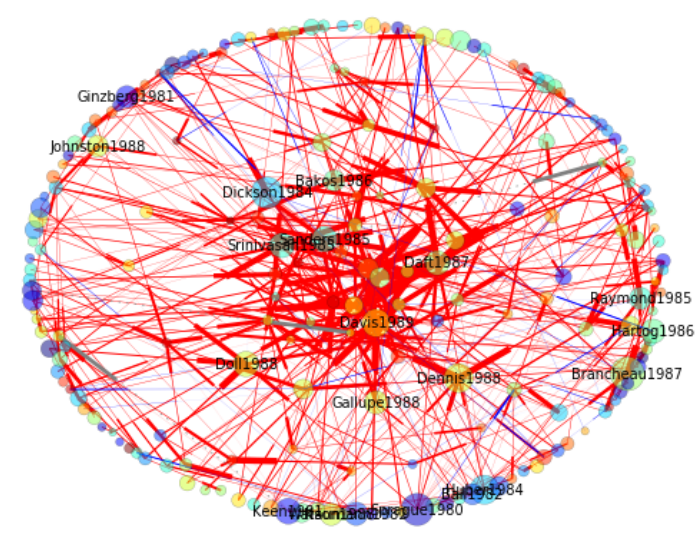

(b) $1987 \sim 1996$

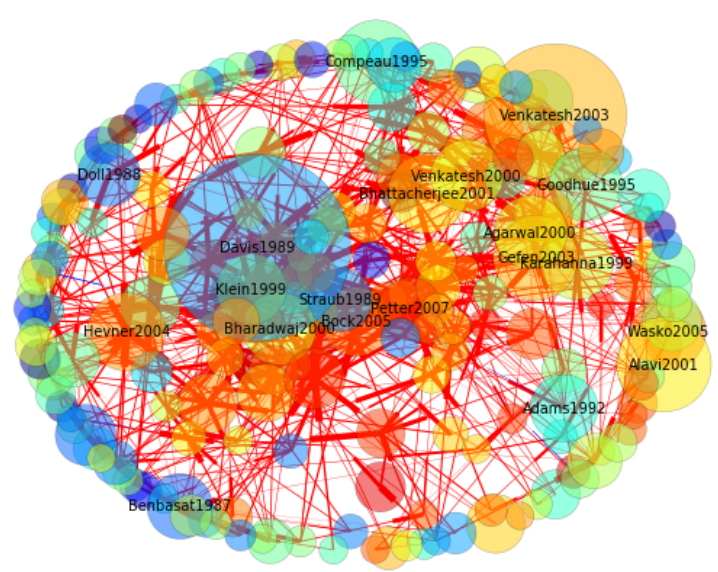

(d) 2007-2016

Figure 2. Citation networks of MIS Quarterly articles in four decades

Table 2. Top five disruptive MISQ articles in the four decades

(a) $1977 \sim 1986$

\begin{tabular}{|c|c|c|c|c|c|c|}
\hline Authors & Year & Vol. & Iss. & Title & $\begin{array}{c}\text { Citations } \\
\text { by } 1986\end{array}$ & $\begin{array}{c}\text { Weighted Avg. } \\
\text { Disruptiveness } 1986\end{array}$ \\
\hline Sprague & 1980 & 4 & 4 & $\begin{array}{l}\text { A framework for the development of decision } \\
\text { support systems }\end{array}$ & 42 & 0.8636 \\
\hline Dickson et al. & 1984 & 8 & 3 & Key information-systems issues for the $1980 \mathrm{~s}$ & 7 & 0.6250 \\
\hline Rockart et al. & 1982 & 6 & 5 & $\begin{array}{l}\text { Future role of the information systems } \\
\text { executive }\end{array}$ & 4 & 0.5905 \\
\hline Ginzberg & 1981 & 5 & 2 & $\begin{array}{l}\text { Key recurrent issues in the MIS } \\
\text { implementation process }\end{array}$ & 12 & 0.5000 \\
\hline Baroudi & 1985 & 9 & 4 & $\begin{array}{l}\text { The impact of role variables on IS personnel } \\
\text { work attitudes and intentions }\end{array}$ & 1 & 0.5000 \\
\hline
\end{tabular}


(b) 1987 1996

\begin{tabular}{|c|c|c|c|l|c|c|}
\hline Authors & Year & Vol. & Iss. & \multicolumn{1}{|c|}{ Title } & $\begin{array}{c}\text { Citations } \\
\text { by 1996 }\end{array}$ & $\begin{array}{c}\text { Weighted Avg. } \\
\text { Disruptiveness }\end{array}$ \\
\hline Sprague & 1980 & 4 & 4 & $\begin{array}{l}\text { A framework for the development of } \\
\text { decision support systems }\end{array}$ & 131 & 0.9338 \\
\hline Pyburn & 1983 & 7 & 2 & $\begin{array}{l}\text { Linking the MIS plan with corporate } \\
\text { strategy: an exploratory study }\end{array}$ & 42 & 0.9333 \\
\hline $\begin{array}{c}\text { Ives \& } \\
\text { Jarvenpaa }\end{array}$ & 1991 & 15 & 1 & $\begin{array}{l}\text { Applications of global information } \\
\text { technology - key issues for management }\end{array}$ & 21 & 0.8750 \\
\hline Daft et al. & 1987 & 11 & 3 & $\begin{array}{l}\text { Message equivocality, media selection, and } \\
\text { manager performance - implications for } \\
\text { information-systems }\end{array}$ & 75 & 0.7136 \\
\hline Davis & 1989 & 13 & 3 & $\begin{array}{l}\text { Perceived usefulness, perceived ease of use, } \\
\text { and user acceptance of information } \\
\text { technology }\end{array}$ & 97 & 0.7054 \\
\hline
\end{tabular}

(c) 1997 2006

\begin{tabular}{|c|c|c|c|l|c|c|}
\hline Authors & Year & Vol. & Iss. & \multicolumn{1}{|c|}{ Title } & $\begin{array}{c}\text { Citations } \\
\text { by 2006 }\end{array}$ & $\begin{array}{c}\text { Weighted Avg. } \\
\text { Disruptiveness } 2006\end{array}$ \\
\hline Pyburn & 1983 & 7 & 2 & $\begin{array}{l}\text { Linking the MIS plan with corporate strategy: } \\
\text { an exploratory study }\end{array}$ & 60 & 0.9524 \\
\hline Davis & 1989 & 13 & 3 & $\begin{array}{l}\text { Perceived usefulness, perceived ease of use, } \\
\text { and user acceptance of information technology }\end{array}$ & 790 & 0.9112 \\
\hline Sprague & 1980 & 4 & 4 & $\begin{array}{l}\text { A framework for the development of decision } \\
\text { support systems }\end{array}$ & 159 & 0.9107 \\
\hline $\begin{array}{c}\text { Ives \& } \\
\text { Jarvenpaa }\end{array}$ & 1991 & 15 & 1 & $\begin{array}{l}\text { Applications of global information technology } \\
\text { - key issues for management }\end{array}$ & 55 & 0.8983 \\
\hline Benbasat et al. & 1987 & 11 & 3 & $\begin{array}{l}\text { The case research strategy in studies of } \\
\text { information-systems }\end{array}$ & 185 & 0.8270 \\
\hline
\end{tabular}

(d) 2007 2016

\begin{tabular}{|c|c|c|c|l|c|c|}
\hline Authors & Year & Vol. & Iss. & \multicolumn{1}{|c|}{ Title } & $\begin{array}{c}\text { Citations } \\
\text { by 2016 }\end{array}$ & $\begin{array}{c}\text { Weighted Avg. } \\
\text { Disruptiveness 2016 }\end{array}$ \\
\hline Davis & 1989 & 13 & 3 & $\begin{array}{l}\text { Perceived usefulness, perceived ease of use, } \\
\text { and user acceptance of information technology }\end{array}$ & 4294 & 0.9779 \\
\hline Watson et al. & 2010 & 34 & 1 & $\begin{array}{l}\text { Information systems and environmentally } \\
\text { sustainable development: energy informatics } \\
\text { and new directions for the IS community }\end{array}$ & 67 & 0.9645 \\
\hline Pyburn & 1983 & 7 & 2 & $\begin{array}{l}\text { Linking the MIS plan with corporate strategy: } \\
\text { an exploratory study }\end{array}$ & 74 & 0.9487 \\
\hline $\begin{array}{c}\text { Cotteleer \& } \\
\text { Bendoly }\end{array}$ & 2006 & 30 & 3 & $\begin{array}{l}\text { Order lead-time improvement following } \\
\text { enterprise information technology } \\
\text { implementation: an empirical study }\end{array}$ & 40 & 0.9302 \\
\hline Sprague & 1980 & 4 & 4 & $\begin{array}{l}\text { A framework for the development of decision } \\
\text { support systems }\end{array}$ & 202 & 0.9289 \\
\hline
\end{tabular}

For each of the four stages, we perform a correlation analysis between the number of citations and disruptiveness index, as shown in Table 3. It shows that there is a positive correlation between the two measures. Highly cited articles are more likely to be impactful to a field, but the correlation strength is only moderate. In other words, disruptiveness is telling us something about these articles that cannot be fully explained by citation count.

These findings suggest that our proposed measure of disruptiveness, provides a new dimension of evaluating the impact of an article in the literature. 
Table 3. Correlation analysis between citations and disruptiveness

\begin{tabular}{|c|c|}
\hline Years & Pearson's Correlation \\
\hline $1979 \sim 1986$ & 0.4361 \\
$1987 \sim 1996$ & 0.4484 \\
$1997 \sim 2006$ & 0.4372 \\
$2007 \sim 2016$ & 0.3683 \\
\hline
\end{tabular}

\subsection{Change of disruptiveness over time}

The disruptiveness index we introduce in this article is not a static measure but a dynamic measure that can change as time passes and new articles join the citation network by citing the prior arts.
Therefore, it would be interesting to analyze how an article's disruptiveness score changes over time, which can provide insights into the development trajectory of a topic or even a field.

In this study, we select the top five most cited MISQ articles and plot their citation counts and disruptiveness scores in a line chart. Since Alavi's and Leidner's 2001 article[11] did not cite any MISQ articles according to Web of Science, its disruptiveness score in MISQ remains zero. Thus, we do not include its analysis below. In Figure 3(a) (d), we can see that:

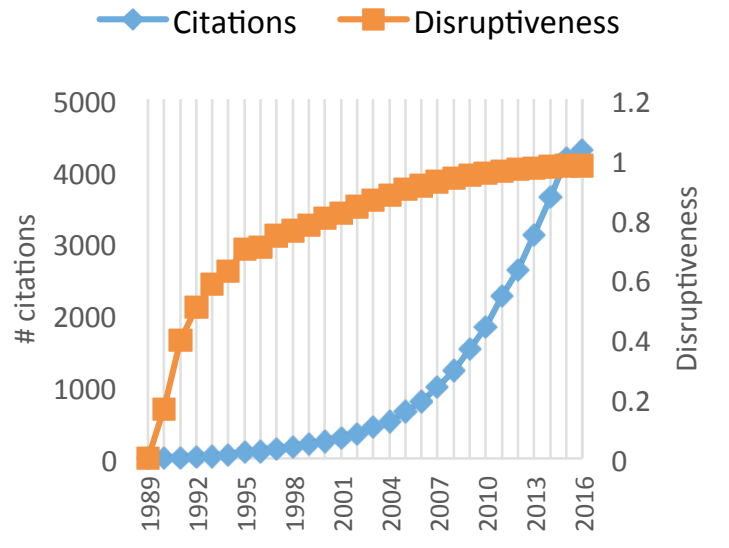

(a) Davis, 1989

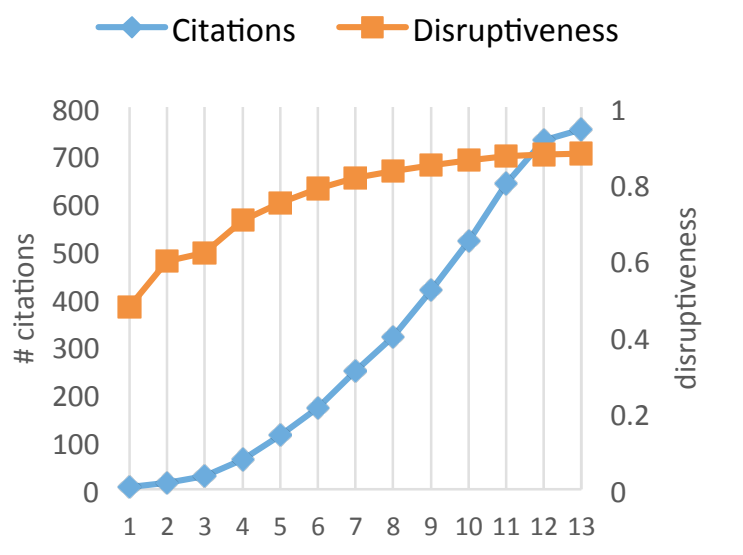

(c) Hevner et al., 2004

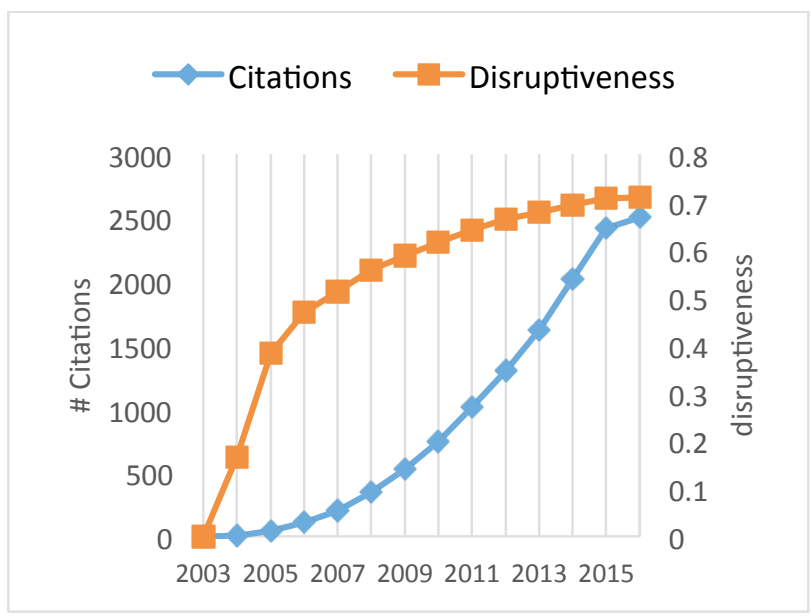

(b) Venkatash et al. 2003

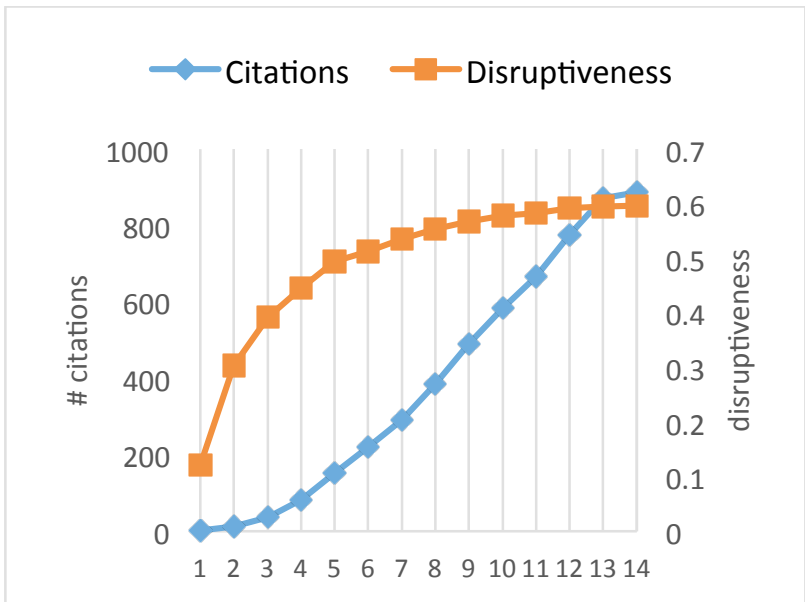

(d) Gefen et al., 2003

Figure 3. Citations and disruptiveness of the five most cited MISQ articles 
- From the day an article is published, it will receive more and more citations as time passes, as illustrated by the monotonic increase of the citation curves. These four articles have received hundreds and even thousands of citations. The large citation count indicates their significance impact in the field of IS.

- All of the four disruptiveness curves also show a monotonic increasing trend over time.

- For these four articles, the citation lines all start off at a small slope, i.e., low increasing rate. After a few years, the curve ticks up and accelerates in the process of accumulating more citations.

- Unlike the "slow-start" citation lines, the disruptiveness lines demonstrate a completely different shape. For these highly impactful articles, we tend to see a rapid increase in its disruptiveness score within the first couple of years. Then, as time passes, the changes in disruptiveness score tend to slow down gradually until it converges. Such a "quick-start" shape makes our proposed disruptiveness index an early detector of impactful work in a field. Without waiting for years before an article receives sufficiently large number of citations, we can look at its disruptiveness score after a much shorter time to forecast its future impact to the field. This also explains why, in Section 4.3, we could identify the fairly recent publication, e.g., [Watson et al., 2001], with a relatively small number of citations, as one of the most disruptive work.

- Another interesting thing we found is with the disruptiveness line in Figure 3(c). Unlike the other three charts, in which the disruptiveness starts with a small value near zero, this article's disruptiveness score was nearly 0.5 already in the year of publication. Since then, it keeps increasing until it reaches 0.9 by far. This was the famous Hevner et al.'s 2004 article "Design science in information systems research."[12] This article categorizes the IS discipline into two paradigms: behavioral science and design science. It provides a conceptual framework and guidelines for conducting design-science research. When it was published in 2004, it became an instant "hit" and stimulated a number of design-science research, including a MISQ special issue on design science research in 2008. The high disruptiveness score this article received in the first year (2004) provides an early and strong predictor of the upcoming knowledge shift towards more design-science research in MISQ.

\section{Conclusions and future directions}

While citation impact, the current central metric to assessing scholarship, can measure the magnitude of the future usage of an article, it cannot capture the substantial effects that an article may have on the subsequent use of its predecessors - whether it amplifies or disrupts the existing literature. The quest for citation impact without distinction between two routes of scholarship is argued to partially contribute to limitations of the current management literature such as lack of original theories. We then embrace that it is imperative to not only assess the impact of an article but also assess how it reinforces the existing research streams or breaks into a new stream to understand its true effect. Accordingly, we introduce the dynamic disruptiveness index of scholarship, and conduct a case study using all articles published in 1979 2016 at MISQ to illustrate the validity of the dynamic measure of scholarship. The empirical results suggest the difference between citation counts and the disruptiveness index with some interesting findings.

This study suffers several limitations and points out future research directions. First, our analysis only focuses on a small set of articles from one journal (MISQ) and one database (Web of Science). Further research is needed to expand the scope of the dataset by including other journals/databases and compute the disruptiveness of an article in terms of its all predecessors. Second, since our current approach only analyzes the citation links without looking at the content, we cannot differentiate articles by their approaches (e.g., quantitative or qualitative) or the reasons for citation (e.g., theoretical foundation or criticism). We also plan to use text analytics approaches to enrich our citation analysis on scientific articles. Third, the objective of this paper is to introduce the disruptiveness index to complement the citation measures, hence we only describe the differences and meanings of the two types of measurement without conducting a systematic and rigorous test. We will further assess its validity by examining if and how a variety of factors such as characteristics of articles, authors, and journals influence the disruptiveness index and impact factor differently.

Finally, and most importantly, it is imperative to examine whether and how the two measures 
correspond to the routes toward normal science or paradigm shift, respectively, in different disciplines. For example, it is critical to ask whether, by adopting a new disruptiveness index to assess scholarship, scholars will tend to take an indigenous approach, focusing more on phenomena-driven and inductive research, and will be more willing to break existing paradigms. If the disruptiveness index will be established as a measure to assess the performance or impact of author, journal, or institution, the research community should focus on more revolutionary research rather than normal science. This is because researchers will care about more the real impact of their research in terms of new knowledge creation rather than big number of citations or knowledge usage. While high number of citations could come from different reasons including real new knowledge, the disruptive index can capture new knowledge creation. By changing measurement criteria, communities can construct niches to favor such a direction so that different types of journals may emerge. Hence, the community caring about new knowledge creation may not target the existing high impact journals that appreciate the number of citations more than knowledge creation.

In this study, we only take the first step to embrace the disruptiveness index. Upon its further validation, such an index can have board theoretical, managerial, and policy implications. We hope such a new measure will be adopted to assess scholarship, for example, in Google Scholar and Web of Science. We hope using this index may facilitate new trends of scholarship toward divergence rather than convergence and toward indigenous rather than formative approach.

\section{References}

[1] T. S. Kuhn, The Structure of Scientific Revolutions . University of Chicago Press, Chicago IL, 1996.

[2] R. Funk and J. Owen-Smith, "A Dynamic Network Measure of Technological Change," Management Science, in press.

[3] C. Oswick, P. Fleming, and G. Hanlon, "From Borrowing to Blending: Rethinking the Processes of Organizational Theory Building," Academy of Management Review, vol. 36, 2011, pp. 318-337.

[4] K. Leung, "The glory and tyranny of citation impact: an East Asian perspective," Academy of Management Journal vol. 50, 2007, pp. 510-514.

[5] H. Barkema, X. Chen, G. George, Y. Luo, and A. Cui, "West meets East: New concepts and theories," Academy of Management Journal, vol. 58, 2015, pp. 460-479.

[6] T. Judge, D. Cable, A. Colbert, and S. Rynes, "What causes a management article to be cited article, author or journal?," Academy of Management Journal, vol. 50, 2007, pp. 491-506.

[7] R. Monastersky, "The number that's devouring sci ence," Chronicle of Higher Education, vol. 52, 2005, pp. Al 2.

[8] W. B. Arthur, The Nature of Technology: What It Is and How It Evolves. Free Press, 2009.

[9] J. A. Schumpeter, Capitalism, socialism and democracy Routledge, 1942.

[10] F. Davis, "Perceived Usefulness, Perceived Ease of Use, and User Acceptance of Information Technology," MIS Quarterly, vol. 13, 1989, pp. 319-340.

[11] M. Alavi and D. Leidner, "Review: Knowledge Management and Knowledge Management Systems: Conceptual Foundations and Research Issues," MIS Quarterly, vol. 25, 2001, pp. 107-136.

[12] A. Hevner, S. March, J. Park, and S. Ram, "Design Science in Information Systems Research.," MIS Quarterly, vol. 28, 2004, pp. 75-105. 